\title{
Artificial Intelligence Based Authentication Technique With Three Entities In 3-G Mobile Communications
}

\author{
Pijush Kanti Bhattacharjee, Member, IACSIT, Chandan Koner, Member, IACSIT, \\ Chandan Tilak Bhunia, Sr. Member, IEEE and Ujjwal Maulik, Sr. Member, IEEE
}

\begin{abstract}
Voice frequency pattern is asymmetric just like nature. Although voice frequency lies between $0 \sim 3.5 \mathrm{KHz}$, a person talking some specific word in different times is always consisting of a very narrow range of frequencies which are varying person to person. Voice frequency of the selective words used by the subscriber at the beginning of conversation like Hello, Good Morning, Namaskar etc is taken as first entity for authentication purpose. We propose second entity as probability of salutation or greeting word from subscriber's talking habit (set of salutation words) whiles the subscriber starts a call. Third entity is chosen as probable location (place) of the subscriber from the selective locations at the time of initializing a call i.e. distance between the subscriber and the network. These three entities such as probability of particular range of frequencies for the salutation word, particular salutation or greeting word, location at the time of starting a call are used with most frequently, more frequently and less frequently by the subscriber like uncertainty in Artificial Intelligence (AI). Now different relative grades are assigned for most frequently, more frequently and less frequently used parameters and the grades are modified according to the assigned weightage of the relative grades. Then Fuzzy operations are performed on modified relative grades (sets). We invent a Fuzzy Rule (condition). If the results obtained from fuzzy operations are satisfied by the invented fuzzy rule, the subscriber (MS) and the network (MSC or PDSN) is mutually authenticated in 3-G mobile communications.
\end{abstract}

Index Terms-AAA server, Artificial Intelligence, Fuzzy set, Fuzzy operation, Subscriber (MS), Network (MSC or PDSN), SIM, Salutation word, USIM.

\section{INTRODUCTION}

Artificial Intelligence (AI) is a theory based on

Pijush Kanti Bhattacharjee is an Assistant Professor in the Department of Electronics and Communication Engineering, Bengal Institute of Technology and Management, Santiniketan, WB, India. He was an Ex Asssitant Director in the Department of Telecommunications (DoT), Government of India, India. He is a member of IACSIT, IAEng, CSTA, IE. (phone: +91-33-25954148; email: pijushbhatta_6@hotmail.com).

Chandan Koner is an Assistant Professor in the Department of Computer Science and Engineering, Bengal Institute of Technology and Management, Pin-731236, WB, India. He is pursuing PhD course.

(phone: +91-9434535556; email: chandan_durgapur@yahoo.com).

Chandan Tilak Bhunia is a Director, Bengal Institute of Technology and Management, Santiniketan, Pin-731236, India. He is a Senior Member of IEEE, FIE (I) and FIETE.

(phone: +91-9434033157; email: ctbhunia@vsnl.com).

Ujjwal Maulik is currently a Professor in the Department of Computer Science and Technology, Jadavpur University, Kolkata, India. (phone: +91-33-24131766; email: ujjwal_maulik@yahoo.com). uncertainty. Fuzzy operations [6] can be performed for taking decision in AI based application. AI can be applied in such applications which are based on uncertainties like vagueness, ambiguity and imprecision. Subscriber's talking habit is also based on uncertainties.

This provides a research challenge for application of AI on subscriber authentication. We propose to use parameter of subscriber's talking habit. It means which particular range of frequency of the salutation (greeting) word, salutation word, location (place) are used with most frequently, more frequently, less frequently by a subscriber while initializing the call. By applying theory of AI, different relative grades can be assigned for most frequently, more frequently, less frequently used parameters considering talking pattern of the subscriber. Fuzzy sets are derived from the modified relative grades which are obtained by assigning weightage. Then fuzzy operations are performed on fuzzy sets, results of fuzzy operations are analyzed by setting an invented fuzzy rule or condition. If the results are satisfying the fuzzy rule, the subscriber (MS) as well as the network (MSC or PDSN) is authenticated, otherwise not.

Thus we propose an AI based subscriber authentication scheme that will check the authenticity of a subscriber by fuzzy operations on fuzzy sets which are derived from talking habit of the subscriber especially salutation word and location of the subscriber at the time of starting a call.

\section{AuthentiCATION TeChNiQue In 3-G MobILE COMMUNICATIONS NETWORK}

In 3-G mobile communication, voice communication is held by MSC (Main Switching Center) and its accessories. In packet switching, authentication is done separately by PDSN (Packet Data Serving Node) servers [1], [4], [5]. The existing authentication technique is described below.

In circuit switching, the authentication for establishing voice path is done by the following procedure,

1) Mutual authentication where MS and MSC are confirmed identity individually.

2) Assure that the authentication information and keys are not being re-used (key freshness).

Additional parameters and cryptographic checks are introduced in 3-G network to provide mutual entity authentication between the USIM (Universal Subscriber Identity Module) at the user side and the AUC 
(Authentication Center) at the network side. This technique uses symmetric key or code using a secret subscriber authentication key $\mathrm{K}$ which is shared between and available only to the USIM and the AUC in the user's HE (Home Environment). In addition, the AUC entrusts with track of a counter $\mathrm{SQN}_{\mathrm{HE}}$ and at the same time USIM controls track of a counter $\mathrm{SQN}_{\mathrm{MS}}$. It also stores additional data to support network authentication providing the user with assurance by key freshness. This scheme is assembled of a challenge/response protocol identical to the 2-G mobile subscriber authentication with an additional feature of network authentication. The HE, which manages both the AUC and the USIM, possesses some technique in the management of sequence numbers.

\section{A. Authentication for Circuit Switching in 3-G Mobile Communications Network}

Authentication in the $3 \mathrm{G}$ network utilizes following Challenge/Response mechanism [1],

1) The VLR (Visitor Location Register) sends a request to the user's AUC.

2) After receiving the request the AUC generates an ordered array of $n$ quintets which are being sent to the VLR. Each quintet consists of the following components, such as Challenge (RAND), Expected response (XRES), Cipher key (CK), Integrity key ФIK), Authentication token $(\mathrm{AUTN} \oplus$ = SQN [ AK] $\|$ AMF $\|$ MAC-A). [where is bit wise EX-OR operation] The AUC generates each quintet by the following procedure:

- Generates a fresh sequence number SQN from a counter $\mathrm{SQN}_{\mathrm{HE}}$.

- Generates an unpredictable challenge RAND.

- Computes a message authentication code for authentication MAC-A $=\mathrm{fl}_{\mathrm{K}}$ (SQN $\|$ RAND $\|$ AMF) where $\mathrm{fl}$ is a message authentication function;

- Computes an expected response XRES $=\mathrm{f} 2_{\mathrm{K}}$ (RAND), where $\mathrm{f} 2$ is a (possibly modified) message authentication function;

- $\quad$ Computes a cipher key $\mathrm{CK}=\mathrm{f}_{\mathrm{K}}$ (RAND), integrity key $\mathrm{IK}=\mathrm{f} 4_{\mathrm{K}}(\mathrm{RAND})$ and anonymity key $\mathrm{AK}=\mathrm{f} 5_{\mathrm{K}}$ (RAND), where f3, f4, f5 are key generating functions.

- Computes the concealed sequence numbe $\oplus$ SQN AK.

- Assembles the authentication token AUTN = SQ $\$$

AK] $\|$ AMF $\|$ MAC-A and the quintet $\mathrm{Q}=$ (RAND, XRES, CK, IK, AUTN) and updates the counter SQN $\mathrm{HE}_{\mathrm{H}}$.

3) AUC sends that ordered array of n quintets to the VLR.

4) When the VLR initiates the authentication scheme it selects the next quintet from an array held in the VLR and sends the parameters RAND and AUTN to the user.

5) After receiving of a (RAND, AUTN) from the VLR, USIM in MS computes the following procedure:

- If the se nonymity key $\mathrm{AK}=\mathrm{f5K}$ (RAND) and retrieves from quence number is concealed, the USIM computes the a AUTN the unconcealed sequerfe number $\mathrm{SQN}=(\mathrm{SQN} \quad \mathrm{AK})$.

- $\quad$ The USIM then computes XMAC-A = f1K (SQN
RAND \| AMF) and compares XMAC-A with MAC-A which is included in AUTN.

- If they are not matching i.e. MAC-A $\neq$ XMAC-A, the USIM directs the MS to fail a user authentication response with indication of integrity failure to the VLR and cancels the further execution.

If they are matched i.e. MAC-A = XMAC-A, the USIM computes the following:

- he USIM verifies that the received sequence number SQN is acceptable or not.

- If the sequence number SQN is not acceptable, the USIM computes the re-synchronization token AUTS and directs the MS to fail a user authentication response, with an indication of synchronization failure, including the re-synchronization token AUTS and abandons the procedure.

If SQN is acceptable, the USIM progresses through the following procedures:

- $\quad$ The USIM then computes the response RES = $\mathrm{f} 2_{\mathrm{K}}$ (RAND) and directs the MS to send back a user authentication response back to the VLR, with an indication of successful receipt of the signed challenge and including the response RES.

6) The VLR compares the received RES with XRES. If they identical, the VLR confirms that the MS (USIM) is authentic and therefore authentication proceeding is successfully completed.

\section{B. Authentication for Packet Switching in 3-G Mobile Communications Network}

Authentication for packet switching [3] is done by AAA (Authentication, Authorization and Accounting) server [1], [4], [5]. Authentication requires the user to provide an account number or identifier and password i.e. exchange of logical keys or certificates between the client (MS) and the server in PDSN. If this authentication is correct, then MS is permitted for packet data service by Authorization.

An AAA server is a server program that handles user requests for access to network resources. The AAA server typically interacts with network access and gateway servers and with databases and directories containing user information.

\section{Proposed ARTIFICIAL INTELLIGENCE BASED AuthenTICATION TECHNIQUE IN 3-G MOBILE COMMUNICATIONS NETWORK}

The proposed artificial intelligence based authentication scheme can be applied to either circuit switching or packet switching mobile communications network to provide voice, data, multimedia services etc. It is a collection of two different phases, namely, Subscriber Enrollment Phase and Subscriber Authentication Phase. These two phases are explained below.

\section{A. Subscriber Enrollment Phase}

In subscriber enrollment phase, the subscriber is enrolled to particular AAA server or switch belonging to the network. This phase is executed only once for one subscriber.

ASE1: The subscriber sends an application request to the authority concerned (mobile service provider) for new SIM. 
ASE2: After receiving the request, the authority asks to submit his different parameters of talking and tests his different talking habit.

ASE3: After that authority examines those tests thoroughly and performs a feasibility study of talking habit of subscriber. The authority records the followings,

1) Which frequency range in voices is appearing most frequently, more frequently and less frequently used by the subscriber in course of a salutation or greeting word talking? For detecting the voice frequency of a salutation word, highly sophisticated electronics transducer is fitted either at the MS or the server which can detect the exact frequency in $\mathrm{Hz}$.

2) Which salutation words are most frequently, more frequently and less frequently used by the subscriber while start talking?

3) What are most frequently, more frequently and less frequently location (place) of the subscriber with respect to time while starting a call?

ASE4: The authority uses three databases in sever for storing the above subscriber parameters based on talking habit. The first database, $D_{F}$ stores the subscriber most frequently, more frequently and less frequently used voice frequencies for each salutation word and its corresponding relative grades. The first range of voice frequency for the salutation word emanating from the subscriber is $\mathrm{D}_{\mathrm{FR} 1}$ of $\mathrm{D}_{\mathrm{F}}$, which stores the most frequently (dominant) used voice frequency of the salutation word and its relative grade which is assigned by 0.65 . The second class $\mathrm{D}_{\mathrm{FR} 2}$ of $\mathrm{D}_{\mathrm{F}}$, stores the more frequently used voice frequency of the salutation word and its relative grade which is assigned by 0.23 . The third range $D_{F R 3}$ of $D_{F}$, stores the less frequently used voice frequency of the salutation word and its relative grade, assigned by 0.12 . Likewise a database is prepared for voice frequency range most frequently, more frequently and less frequently for predicted all salutation words used by the subscriber. $\mathrm{D}_{\mathrm{FR} 1}, \mathrm{D}_{\mathrm{FR} 2}, \mathrm{D}_{\mathrm{FR} 3}$ of $\mathrm{D}_{\mathrm{F}}$ are calculated as per following formula. Suppose $\mathrm{D}_{\mathrm{F}}$ ranges between a $\mathrm{Hz}$ (lower frequency) to $\mathrm{b} \mathrm{Hz}$ (higher frequency), compute $\mathrm{c}=(\mathrm{a}+\mathrm{b}) / 2$ and $d=(b-a) / 6$ [since three equal divisions are made]. $D_{F R 1}$ ranges between $\mathrm{e}=(\mathrm{c}-\mathrm{d}) \mathrm{Hz}$ to $\mathrm{f}=(\mathrm{c}+\mathrm{d}) \mathrm{Hz}$. $\mathrm{D}_{\mathrm{FR} 2}$ ranges between $\mathrm{g}=(\mathrm{e}-\mathrm{d}) \mathrm{Hz}$ to $\mathrm{h}=(\mathrm{e}-1) \mathrm{Hz}$ and $\mathrm{i}=(\mathrm{f}+1) \mathrm{Hz}$ to $\mathrm{j}=$ $(\mathrm{f}+\mathrm{d}) \mathrm{Hz} . \mathrm{D}_{\mathrm{FR} 3}$ ranges between $\mathrm{k}=(\mathrm{g}-\mathrm{d}) \mathrm{Hz}=\mathrm{a} \mathrm{Hz}$ to $\mathrm{l}=(\mathrm{g}-$ 1) $\mathrm{Hz}$ and $\mathrm{m}=(\mathrm{j}+1) \mathrm{Hz}$ to $\mathrm{n}=(\mathrm{j}+\mathrm{d}) \mathrm{Hz}=\mathrm{b} \mathrm{Hz}$.

The second database, $\mathrm{D}_{\mathrm{W}}$ stores the most frequently, more frequently and less frequently used salutation words (starting time spoken) and their corresponding relative grades. The first row, $\mathrm{D}_{\mathrm{WR} 1}$ of $\mathrm{D}_{\mathrm{W}}$, stores the most frequently used salutation words and their relative grade which is assigned by 0.9 . The second row, $\mathrm{D}_{\mathrm{WR} 2}$ of $\mathrm{D}_{\mathrm{W}}$, stores the more frequently used salutation words and their relative grade which is assigned by 0.6 . The third row, $\mathrm{D}_{\mathrm{WR} 3}$ of $\mathrm{D}_{\mathrm{W}}$, stores the less frequently used salutation words and their relative grade which is assigned by 0.3 .

This first and second databases can be joined together to make one table whose columns are showing different range of voice frequencies with its relative grades for the salutation words (generally divided into three groups), relative grades for the salutation words while the rows are showing the salutation words used by the subscriber.

The third database, $\mathrm{D}_{\mathrm{L}}$ stores the most probable, more probable and less probable location (place) of the subscriber with respect to time while starting a call (i.e. distance of the subscriber from the network which can be measured by received power level) and their corresponding relative grades. This database is divided into two parts, $\mathrm{D}_{\mathrm{L} 1}$ (For the time 9:00 AM to 6:00 PM) and $\mathrm{D}_{\mathrm{L} 2}$ (For the time 6:00 PM to 9:00 AM). The first row, $\mathrm{D}_{\mathrm{L} 1 \mathrm{R} 1}$ of $\mathrm{D}_{\mathrm{L} 1}$, stores the most probable location of subscriber and their relative grade which is assigned by 0.9 . The second row, $\mathrm{D}_{\mathrm{L} 1 \mathrm{R} 2}$ of $\mathrm{D}_{\mathrm{L} 1}$, stores the more probable location of subscriber and their relative grade which is assigned by 0.6 . The third row, $D_{\text {L1R3 }}$ of $\mathrm{D}_{\mathrm{L} 1}$, stores the less probable location of subscriber and their relative grade which is assigned by 0.3 .

The first row, $\mathrm{D}_{\mathrm{L} 2 \mathrm{R} 1}$ of $\mathrm{D}_{\mathrm{L} 2}$, stores the most probable location of subscriber and their relative grade which is assigned by 0.9 . The second row, $\mathrm{D}_{\mathrm{L} 2 \mathrm{R} 2}$ of $\mathrm{D}_{\mathrm{L} 2}$, stores the more probable location of subscriber and their relative grade which is assigned by 0.6 . The third row, $\mathrm{D}_{\mathrm{L} 2 \mathrm{R} 3}$ of $\mathrm{D}_{\mathrm{L} 2}$, stores the less probable location of subscriber and their relative grade which is assigned by 0.3 .

Since these three parameters are completely different and independent to each other, therefore to make a fuzzy relation with mutual exclusive functions, we are imposing different weightage to these parameters. The ratio of weightage is considered like, $\mathrm{D}_{\mathrm{F}}: \mathrm{D}_{\mathrm{W}}: \mathrm{D}_{\mathrm{L}}=1: 1.5: 2$. We are dividing relative grades by corresponding weightage to have modified relative grades.

ASE5: If the authority does not get sufficient information, request for resubmission correct signature or database of the subscriber is placed. Then the authority executes the above steps again to create a strong database.

\section{B. Subscriber Authentication Phase}

When a subscriber requests for connecting a call, an announcement from the server (switch) may be issued to speak the salutation word which is intending to use by the subscriber for the called subscriber. After receiving the salutation word from the calling subscriber, authentication process starts. If successfully authenticated, the calling subscriber is extended connection to the called subscriber, otherwise connection is denied. Thus after receiving the salutation or greeting word from a calling subscriber at the starting time of a call, the server (switch) executes the following operations:

ASA1: Finds the matched frequency of the salutation word within the rows $\mathrm{D}_{\mathrm{FR} 1}, \mathrm{D}_{\mathrm{FR} 2}, \mathrm{D}_{\mathrm{FR} 3}$ of $\mathrm{D}_{\mathrm{F}}$.

ASA1.1: After hearing the first speech from a subscriber, either MS or server computes frequency of the salutation word in $\mathrm{Hz}$, then match the voice frequency within the stored range of $D_{F}$ and its corresponding relative grade which is taken as $\mathrm{v} 1$, if not match $\mathrm{v} 1=0$.

The membership functions of a fuzzy set F1 can be defined as follows,

$\mu_{\mathrm{F} 1}(\mathrm{a} 1)=\mathrm{v} 1$,

Hence, $\mathrm{F} 1=\{(\mathrm{a} 1, \mathrm{v} 1)\}$

ASA2: Finds the matched salutation or greeting word within the rows $\mathrm{D}_{\mathrm{WR} 1}, \mathrm{D}_{\mathrm{WR} 2}, \mathrm{D}_{\mathrm{WR} 3}$ of $\mathrm{D}_{\mathrm{W}}$.

ASA2.1: If the salutation word is matched within the stores value of $D_{\mathrm{WR} 1}, \mathrm{D}_{\mathrm{WR} 2}, \mathrm{D}_{\mathrm{WR} 3}$, then it stores $\mathrm{w} 1=$ 
Relative grade of the matched salutation word in row, otherwise $w 1=0$. The modified value of $w 1$ according to weightage is $\mathrm{w} 1_{\mathrm{m}}$, where $\mathrm{w} 1_{\mathrm{m}}=(\mathrm{w} 1) / 1.5$,

The membership functions of a fuzzy set F2 can be defined as follows,

$\mu_{\mathrm{F} 2}(\mathrm{a} 2)=\mathrm{w} 1_{\mathrm{m}}$

Hence, $\mathrm{F} 2=\left\{\left(\mathrm{a} 2, \mathrm{w} 1_{\mathrm{m}}\right)\right\}$

ASA3: Server watches the time and selects the database for location of the subscriber $\left(\mathrm{D}_{\mathrm{L} 1}\right.$ or $\left.\mathrm{D}_{\mathrm{L} 2}\right)$ at the starting time of a call. Finds the matched location within the rows DL1R1, DL1R2, $D_{L 1 R 3}$ for $D_{L 1}$ or $D_{L 2 R 1}, D_{L 2 R 2}, D_{L 2 R 3}$ for $D_{L 2}$ depending on call initializing or starting time.

ASA3.1: If the location of the MS is matched, then stores $\mathrm{p} 1=$ Relative grade of matched location in row, otherwise $\mathrm{p} 1=0$. The modified value of $\mathrm{p} 1$ according to the weightage is $\mathrm{p} 1_{\mathrm{m}}$, where $\mathrm{p} 1_{\mathrm{m}}=(\mathrm{p} 1) / 2$,

The membership functions of a fuzzy set F3 can be defined as follows,

$\mu_{\mathrm{F} 3}(\mathrm{a} 3)=\mathrm{p} 1_{\mathrm{m}}$

Hence, $\mathrm{F} 3=\left\{\left(\mathrm{a} 3, \mathrm{p} 1_{\mathrm{m}}\right)\right\}$

ASA4: Computes fuzzy operations, (a3)\}

ASA4.1: $\mu_{\mathrm{F} 1} \cap_{\mathrm{F} 2} \cap_{\mathrm{F} 3}(\mathrm{a})=\min \left\{\mu_{\mathrm{F} 1}(\mathrm{a} 1), \mu_{\mathrm{F} 2}(\mathrm{a} 2), \mu_{\mathrm{F} 3}\right.$

ASA4.2: $\mu_{\mathrm{F} 1} \cup \mathrm{F} \cup \mathrm{F} 3(\mathrm{a})=\max \left\{\mu_{\mathrm{F} 1}(\mathrm{a} 1), \mu_{\mathrm{F} 2}(\mathrm{a} 2)\right.$, $\left.\mu_{\mathrm{F} 3}(\mathrm{a} 3)\right\}$

ASA5: For ascertaining the mobile subscriber (MS) as well as the network (MSC or PDSN) authenticity, an invented Fuzzy Rule (condition) on result of the fuzzy operations has been implied.

If $\mu_{\mathrm{F} 1} \cap_{\mathrm{F} 2} \cap_{\mathrm{F} 3}(\mathrm{a}) \geq 0.15$ and $\mu_{\mathrm{F} 1} \cup \mathrm{F} 2 \cup \mathrm{F} 3(\mathrm{a}) \geq 0.45$ satisfies, then only the server ensures that the subscriber is authentic, hence their mutual authenticity is verified. The server checks or computes the authentication process. Since primary databases are kept at the server (switch), if that stored values in respect of the parameters of the subscriber at the server are not matched with that of the subscriber as currently transmitted, further processing will be stopped which identifies that the network is unauthentic. Also if the above two fuzzy conditions are not satisfied, the server ensures that the user or the subscriber (MS) is unauthentic. In both the cases the server sends an authentication failure message to the subscriber.

\section{IV.RESUlTS AND DisCUSSION}

First of all the feasibility study of all subscribers talking habit from subscriber test and documents are made and the authority stores in server (switch) those databases having different parameters with values.

Example1: A subscriber starts talking with "Namaskar" in $2325 \mathrm{~Hz}$ on 10:24 AM at home, examine authenticity of the subscriber and the network.

After testing voice frequency of the subscriber's salutation word "Namaskar" stored in the server, the range of voice frequency of the subscriber's particular salutation word "Namaskar" is found from $2235 \mathrm{~Hz}$ to $2726 \mathrm{~Hz}$.

If the voice frequency of the subscriber's salutation word "Namaskar" is within $2398 \mathrm{~Hz}$ to $2562 \mathrm{~Hz}$ then the value $\mathrm{D}_{\mathrm{FR} 1}$ of $\mathrm{D}_{\mathrm{F}}$ is 0.65 .
If the voice frequency of the subscriber's salutation word "Namaskar" is within $2316 \mathrm{~Hz}$ to $2397 \mathrm{~Hz}$ and $2563 \mathrm{~Hz}$ to $2645 \mathrm{~Hz}$, the value $\mathrm{D}_{\mathrm{FR} 2}$ of $\mathrm{D}_{\mathrm{F}}$ is 0.23 .

If the voice frequency of the subscriber's salutation word "Namaskar" is within $2235 \mathrm{~Hz}$ to $2315 \mathrm{~Hz}$ and $2646 \mathrm{~Hz}$ to $2726 \mathrm{~Hz}$, the value $\mathrm{D}_{\mathrm{FR} 3}$ of $\mathrm{D}_{\mathrm{F}}$ is 0.12 .

The salutation or greeting words are stored in the server for the subscriber in $\mathrm{D}_{\mathrm{WR} 1}$ of $\mathrm{D}_{\mathrm{W}}$ like,

Hello, Oh God, Jai-Ram, Adab, Namaste.

The salutation words are stored in the server for the subscriber in $\mathrm{D}_{\mathrm{WR} 2}$ of $\mathrm{D}_{\mathrm{W}}$ like,

Good Morning, Good Afternoon, Radhe-Radhe, Hi, Kaisa-Hai.

The salutation words are stored in the server for the subscriber in $\mathrm{D}_{\mathrm{WR} 3}$ of $\mathrm{D}_{\mathrm{W}}$ like,

Namaskar, Assalamo-Alaokum, Joyguru, Hare-Ram, Hare-Krishna.

Let the relative grade of $\mathrm{D}_{\mathrm{WR} 1}$ is $0.9, \mathrm{D}_{\mathrm{WR} 2}$ is 0.6 and $\mathrm{D}_{\mathrm{WR} 3}$ is 0.3 .

For salutation word "Namaskar" of the subscriber, it is in $\mathrm{D}_{\mathrm{WR} 3}$ whose relative grade (w1) is 0.3

For the time period 9:00 AM. to 6:00 PM,

If the location of the subscriber is office, the value of $\mathrm{D}_{\mathrm{L} 1 \mathrm{R} 1}$ of $\mathrm{D}_{\mathrm{L} 1}$ is 0.9 .

If the location is tour or elsewhere then the value of $D_{L 1 R 2}$ of $\mathrm{D}_{\mathrm{L} 1}$ is 0.6 .

If the location is home then the value of $D_{L 1 R 3}$ of $D_{L 1}$ is 0.3 .

For the time period 6:00 PM. to 9:00 AM,

If the location is home then the value of $D_{L 2 R 1}$ of $D_{L 2}$ is 0.9 .

If the location is tour or elsewhere then the value of $\mathrm{D}_{\mathrm{L} 2 \mathrm{R} 2}$ of $\mathrm{D}_{\mathrm{L} 2}$ is 0.6 .

If the location is office then the value of $D_{L 2 R 3}$ of $D_{L 2}$ is 0.3 .

The subscriber on 10:24 AM at home falls in $\mathrm{D}_{\mathrm{L} 1 \mathrm{R} 3}$ whose relative grade $(\mathrm{p} 1)$ is 0.3 ,

Hence, the matched frequency of the salutation word $(2325 \mathrm{~Hz})$ from the subscriber in $\mathrm{D}_{\mathrm{FR} 2}$.

Therefore, $\mathrm{v} 1=0.23$

$\mu_{\mathrm{F} 1}(\mathrm{a} 1)=\mathrm{v} 1=0.23$,

Hence, $\mathrm{F} 1=\{(\mathrm{a} 1,0.23)\}$

The matched the salutation (greeting) word of the subscriber in $\mathrm{D}_{\mathrm{WR} 3 \text {. }}$

Therefore, $\mathrm{w} 1=0.3, \mathrm{w} 1_{\mathrm{m}}=\mathrm{w} 1 / 1.5=0.3 / 1.5=0.20$ $\mu_{\mathrm{F} 1}(\mathrm{a} 2)=\mathrm{w} 1_{\mathrm{m}}=0.20$,

Hence, $\mathrm{F} 2=\{(\mathrm{a} 2,0.20)\}$

The matched the location of the subscriber in $\mathrm{D}_{\mathrm{L} 1 \mathrm{R} 3}$.

Therefore, $\mathrm{p} 1=0.3, \mathrm{p} 1_{\mathrm{m}}=\mathrm{p} 1 / 2=0.3 / 2=0.15$ $\mu_{\mathrm{F} 1}(\mathrm{a} 3)=\mathrm{p} 1_{\mathrm{m}}=0.15$,

Hence, $\mathrm{F} 3=\{(\mathrm{a} 3,0.15)\}$

Now, $\mu_{F 1} \cap_{F 2} \cap_{F 3}(a)=\min \{0.23,0.20,0.15\}=0.15$;

$\mu_{\mathrm{F} 1} \cup \mathrm{F} 2 \cup \mathrm{F} 3(\mathrm{a})=\max \{0.23,0.20,0.15\}=0.23$

As fuzzy rule $\mu_{\mathrm{F} 1} \cap_{\mathrm{F} 2} \cap_{\mathrm{F} 3}(\mathrm{a}) \geq 0.15$ and

$\mu_{\mathrm{F} 1} \cup \mathrm{F} 2 \cup \mathrm{F} 3(\mathrm{a}) \geq 0.45$ is not true, so the sever ensures that the subscriber is not authentic; hence they are not mutual authenticated followed by authentication failure message.

Example2. The subscriber (same subscriber as in Ex1) starts talking with "Good Morning" in $1915 \mathrm{~Hz}$ on $7.36 \mathrm{AM}$ while at tour, examine mutual authenticity of the subscriber 
with the network.

After testing voice frequency of the subscriber's salutation word "Good Morning" from the server, the range of voice frequency of the subscriber's particular salutation word "Good Morning" is found from $1734 \mathrm{~Hz}$ to $2256 \mathrm{~Hz}$.

If the voice frequency of the subscriber's salutation word "Good Morning" is within $1908 \mathrm{~Hz}$ to $2082 \mathrm{~Hz}$ then the value $\mathrm{D}_{\mathrm{FR} 1}$ of $\mathrm{D}_{\mathrm{F}}$ is 0.65 .

If the voice frequency of the subscriber's salutation word "Good Morning" is within $1821 \mathrm{~Hz}$ to $1907 \mathrm{~Hz}$ and 2083 $\mathrm{Hz}$ to $2169 \mathrm{~Hz}$, the value $\mathrm{D}_{\mathrm{FR} 2}$ of $\mathrm{D}_{\mathrm{F}}$ is 0.23 .

If the voice frequency of the subscriber's salutation word "Good Morning" is within $1734 \mathrm{~Hz}$ to $1820 \mathrm{~Hz}$ and 2170 $\mathrm{Hz}$ to $2256 \mathrm{~Hz}$, the value $\mathrm{D}_{\mathrm{FR} 3}$ of $\mathrm{D}_{\mathrm{F}}$ is 0.12 .

$\mathrm{D}_{\mathrm{W}}$ and $\mathrm{D}_{\mathrm{L}}$ are remaining same value as in Example1 since the same subscriber is talking, otherwise $\mathrm{D}_{\mathrm{W}}$ and $\mathrm{D}_{\mathrm{L}}$ has to be computed separately.

Hence, the matched frequency of the salutation word $(1915 \mathrm{~Hz})$ from the subscriber in $\mathrm{D}_{\mathrm{FR} 1}$

Therefore, $\mathrm{v} 1=0.65$

$\mu_{\mathrm{F} 1}(\mathrm{a} 1)=\mathrm{v} 1=0.65$,

Hence, $\mathrm{F} 1=\{(\mathrm{a} 1,0.65)\}$

The matched the salutation (greeting) word of the subscriber in $\mathrm{D}_{\mathrm{WR} 2 \text {. }}$

Therefore, $\mathrm{w} 1=0.6, \mathrm{w} 1_{\mathrm{m}}=\mathrm{w} 1 / 1.5=0.6 / 1.5=0.40$, $\mu_{\mathrm{F} 1}(\mathrm{a} 2)=\mathrm{w} 1_{\mathrm{m}}=0.40$,

Hence, $\mathrm{F} 2=\{(\mathrm{a} 2,0.40)\}$

The matched the location of the subscriber in $\mathrm{D}_{\mathrm{L} 2 \mathrm{R} 2}$.

Therefore, $\mathrm{p} 1=0.6, \mathrm{p} 1_{\mathrm{m}}=0.6 / 2=0.30$,

$\mu_{\mathrm{F} 1}(\mathrm{a} 3)=\mathrm{p} 1_{\mathrm{m}}=0.30$,

Hence, $\mathrm{F} 3=\{(\mathrm{a} 3,0.30)\}$

Now, $\mu_{\mathrm{F} 1} \cap_{\mathrm{F} 2} \cap_{\mathrm{F} 3}(\mathrm{a})=\min \{0.65,0.40,0.30\}=0.30$;

$\mu_{\mathrm{F} 1} \cup \mathrm{F} 2 \cup \mathrm{F} 3(\mathrm{a})=\max \{0.65,0.40,0.30\}=0.65$

As fuzzy rule set as, $\mu_{\mathrm{F} 1} \cap_{\mathrm{F} 2} \cap_{\mathrm{F} 3}(\mathrm{a}) \geq 0.15$ and

$\mu_{\mathrm{F} 1} \cup \mathrm{F} 2 \cup \mathrm{F} 3(\mathrm{a}) \geq 0.45$ is true i.e. the fuzzy rule satisfies

results of the fuzzy operations, so the server ensures that the subscriber is authentic, hence they are mutual authenticated.

\section{Advantages Of The Proposed Authentication TECHNIQUE}

This technique is highly efficient due to artificial intelligence used and no further information has to be supplied by the subscriber (MS) while making a call. The characteristics of this authentication scheme are,

1) This mobile subscriber as well as network authentication technique enjoys the advantages of artificial intelligence and fuzzy theory, so it is an unique one.

2) Artificial inteligence is efficiently employed to the server and subsequently it takes part to authenticate correct subscriber as well as network.

3) Authenticity is decided by the subscriber's talking characteristics (habit) and distance of the subscriber from the base station or the network.

4) No cryptography algorithm or any complex functions are applied for authentication purpose.

5) Flexible simple fuzzy operations are performed on fuzzy set for authentication decision.

6) This authentication technique ensures result with in a real time basis.

\section{CONCLUSION}

In our proposed artificial intelligence based technique, subscriber as well as network mutual authentication scheme is developed. A novel artificial intelligence is intoduced to the server for authenticate purpose. In our future work, we will spread out this technique in various wireless communication networks within a real time basis.

\section{REFERENCES}

[1] Rappaport, Wireless Communication: Principles and Practice, Prentice Hall Pub Ltd, 2nd Ed, 2007.

[2] C. T. William C. Y. Lee, Wireless and Cellular Communications, 3rd Edition McGraw Hill Publishers 2008.

[3] T. S. Bhunia, Information Technology Network and Internet, New Age International Publishers, India, 5th Edition (Reprint), 2006.

[4] H. Kim, H. Afifi, "Improving Mobile Authentication With New AAA Protocols", IEEE International Conference on Communication (ICC 2003) vol 1, May, 2003, pp 497-501.

[5] C. Koner, P. K. Bhattacharjee, C. T. Bhunia, U Maulik, "A Novel Approach for Authentication Technique in Mobile Communications", International Journal of Computer Theory and Engineering, Singapore, vol. 1, no. 3, 2009, pp. 225-229.

[6] Vilem Novak, Jiri Mockor, Irina Perfilieva, Mathematical Principles of Fuzzy Logic, Kluwer Academic Publisher, 2006

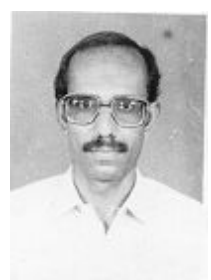

Dr. Pijush Kanti Bhattacharjee is associated with the study of Engineering, Management, Law, IndoAllopathy, Herbal, Homeopathic and Yogic medicines. $\mathrm{He}$ is having qualifications ME, MBA, MDCTech, AMIE, BSc, BA, LLB, BIASM, CMS, PET, EDT, FWT, DATHRY, BMus, KOVID, DH, ACE, FDCI etc. He worked in Department of Telecommunications (DoT), Govt. of India from June 1981 to Jan 2007 (26 years), lastly holding Assistant Director post at RTEC [ER], DoT, Kolkata, India. Thereafter, he worked at IMPS College of Engineering and Technology, Malda, WB, India as an Assistant Professor in Electronics and Communication Engineering Department from Jan,2007 to Feb,2008 and Feb, 2008 to Dec, 2008 at Haldia Institute of Technology, Haldia, WB, India. In Dec, 2008 he joined at Bengal Institute of Technology and Management, Santiniketan, WB, India in the same post and department. He has written two books "Telecommunications India" \& "Computer". He is a Member of IE, ISTE, India; CSTA, USA; IACSIT, Singapore and IAENG, Hongkong. His research interests are in Mobile Communications, VLSI, Network Security etc.

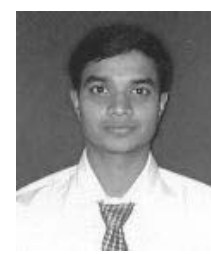

Mr. Chandan Koner did his B.Tech in 2005 and M.Tech in 2007 respectively. He is currently an Assistant Professor in the Department of Computer Science and Engineering, Bengal Institute of Technology and Management, Santiniketan, P.O. Doranda, West Bengal, Pin-731236, India. He is pursuing $\mathrm{PhD}$ course in Computer Science and Engineering from Jadavpur University, Kolkata, India. Mr. Koner is a Member of IACSIT, Singapore and IAENG,Hongkong. His research interests include Mobile Communications, Network Security, Data Mining and Sensor Networks etc.

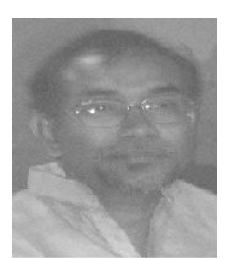

Dr. Chandan Tilak Bhunia did his B. Tech and M. Tech in Radio Physics and Electronics in 1982 and 1984, and Ph.D in Computer Science and Engineering. $\mathrm{He}$ is currently Director, Bengal Institute of Technology and Management, Santiniketan, P.O. Doranda, West Bengal, Pin-731236, India. He is a Senior Associate of International Center for Theoretical Physics (ICTP), Italy. Dr. Bhunia is a Fellow of Institution of Electronics and Telecommunication Engineers (IETE) and Institution of Engineers (IE), India, and a Senior Member of Institute of Electrical and Electronics Engineers (IEEE). His research interests include Mobile Communications, Network Security, Computer Networks, Electronics Semiconductors and Multimedia Systems. 
Dr. Ujjwal Maulik did his BS in Physics and Computer Science in 1986 and 1989 respectively, and MS and Ph.D in Computer Science in 1991 and 1997 respectively. He is currently a Professor in the Department of Computer Science and Technology, Jadavpur University, Kolkata, India. Dr. Maulik received the fellowships from International Center for Pure and Applied Mathematics, CIPA, France, in 1994, 1996 and 2006 and International Center for Theoretical Physics (ICTP), Italy in 2007. Dr. Maulik is also a Fellow of Institution of Electronics and Telecommunication Engineers (IETE) and Institution of Engineers (IE), India, and a Senior Member of Institute of Electrical and Electronics Engineers (IEEE). His research interests include Soft Computing, Pattern Recognition, Data Mining, Bioinformatics, Parallel and Distributed Systems. 